\title{
Sero-Mapping of HBV, HCV, HSV2 and Syphilis Across Regions in Kenya
}

\author{
Mwangi Joseph $^{1} \quad$ Solomon Mpoke $^{1} \quad$ Dama Olungae $^{1} \quad$ Rency Lel $^{1} \quad$ Zipporah Ng'anga $^{2}$ \\ 1.Kenya Medical Research Institute,Centre for Virus Research,Nairobi Kenya \\ 2.Jomo Kenyatta University of Agriculture and Technology,Nairobi Kenya
}

\begin{abstract}
This study was funded by Internal Research Grants of the Kenya Medical Research Institute. We acknowledge support from director KEMRI and institutions that participated in this study.
\end{abstract}

\section{Abstract}

Hepatitis B and C,herpes Simplex Virus 2 and syphilis are important infections that share common modes of transmission. The global burden of these infections and their occurrence as co-infection of HIV in high risk population groups calls for more attention in control and management. While HIV has been a program priority disease in many low resource settings, hepatis B and C have not had as much attention. Yet there is substantial indication that transmission of hepatitis, herpes virus 2 and syphilis is on the increase. This study aimed at determining the prevalence of hepatitis B, hepatitis C, Herpes simples virus 2 and syphilis and their distribution across different regions in Kenya. Samples were collected from HIV positive study participants in 11 counties (out of total 47) distributed in 7 out of the 8 regions (provinces).A total of 1829 samples were tested for the 4 infections and their distribution analysised. Mapping of the infection was presented by study sites and regions . Overall prevalence of HSV2 was the highest (at 50\%) followed by that of HBV $(29 \%)$ and HCV and Syphilis $(14 \%$ repectively). Majority of study participants (71\%) had co-infections while the rest of the study participants (29\%) had none of the four infections. Western and Nyanza regions of the country had higher prevalence of HBV (above $31 \%$ ). Sero-prevalence of HCV across the regions ranged between 8 to 19 percent. Syphilis sero-prevalence was highest in western and Nyanza region (Range 18\% to 26\%) compared to other regions (4\% to15\%), the lowest prevalence was in Central region. Distribution of HSV2 indicated Nairobi was leading at $62 \%$, Central at $48.5 \%$ and Rift Valley at $47.5 \%$. Lowest prevalence of HSV2 was at eastern region with an average of $29 \%$. There was significant relation between infections and study sites. Since routine testing for HBV, HCV and HSV is not readily available, there is need to develop a strategy for prevention and control of these infections. Integration of services would be an important consideration in this regard.

Keywords: HBV, HCV, HSV, Syphilis, prevalence, co-infection, distribution

DOI: $10.7176 / \mathrm{JBAH} / 9-12-06$

Publication date:June $30^{\text {th }} 2019$

\section{Introduction}

Hepatitis B [HBV], Hepatitis C (HBV), and Herpes simplex (HS) are significant viral infections responsible for millions of infections globally. On the other hand, Syphilis, a bacterial infection joins the list of the three viral infections as an important Sexual Transmitted Infection (STI). Viral Hepatitis B and C affects 325 million people globally with the death toll of hepatitis rivaling that of HIV globally. . In Africa, chronic viral hepatitis affects over 70 million, 60 million of this with Hepatitis B and 10 million with Hepatitis C (WHO fact sheets, 2017). Herpes Simplex Virus affects an estimated 500 million people worldwide (Abdool, 2015; Dinesh and Deepak, 2016). Estimates indicate that 417 million people aged 15-49 years had HSV2 infection globally in 2012 and 36 million with syphilis (11 million newly-infected) world-wide (Katharine et al., 2015). Herpes simplex virus type 2 (HSV-2) and syphilis infections are mainly sexually transmitted. Herpes simplex virus 2 causes genital herpes and increases the risk of HIV acquisition by 3 -fold.The resultant co-infection with HIV increases the genital shedding and HIV transmissibility fivefold (Todd et al,2013; Katharine et al., 2015)

Sero-mapping of the four infections is imperative to establish hot spots of infections, the spectrum of diseases, risk factors and potential route of viral transmission. In addition, mapping is equally important (Hay et al, 2013) in assessing risk factors or determinants, disease dynamics, prevention and improved emergency response in order to guide operational models of implementation in prevention and control. There is also need for local, regional and national coordinated response towards these infections within a country.

Besides the individual pathophysiology of HBV, HCV, HSV and Syphilis, these three viruses and a bacterium have an unfortunate synergy with HIV leading to complex co-infections. The organisms share common modes of transmission through sex, intravenous drug use, blood transfusion and vertical transmission (Mavilia and $\mathrm{Wu}$, 2018).

These infections are also underestimated since they are not routinely screened for nor are they part of a repertoire of infections that form laboratory diagnostic workout in most developing countries, especially in African region.

While HIV, HBV, HCV, HSV and syphilis are endemic in Africa, their rates appear highly variable among 
different countries (WHO, 2017). Hepatitis prevalence ranges of 6-20\% (Saraswat et al, 2015; Daw et al, 2014] [WHO, 2017) has been reported. Other studies indicate increased prevalence including $11.2 \%$ and $17.6 \%$ (Cameroon and Uganda) (Mutagoma et al, 2017) and 6.2\%, and $1.1 \%$ in Ethiopia (HBV and syphilis respectively)(Kassa et al,2019).

The most riveting aspect of the above named viruses, despite their public health importance and their potential co-infections with HIV is that there is no dedicated program targeting their control in most developing countries. With the increasing global concern on their effects, the question remains,can these infections have a dedicated program or be included in HIV programming in resource limited settings?

\section{Methods}

\section{Study settings and samples}

A cross sectional study was conducted with samples collected from 7 out of the 8 regions in Kenya. A total of 12 health facilities distributed across the 11 counties were identified for the study. Facilities selected were those providing comprehensive care services (CCC, specialized clinics for HIV and AIDS) and a blood transfusion center. Upon consent samples were collected, de-identified and anonymised after separation and shipped to the Centre for Virus Research, HIV and AIDS laboratory, Kenya Medical Research Institute for testing. The study analyzed a total of 1829 samples collected through random selection of study participants.

\section{Ethical consideration}

This study was approved by scientific and ethical review board of Kenya Medical Research Institute. Participants were voluntary recruited and consented to participate in the study.

\section{Laboratory procedures}

All samples were first retested for HIV using Rapid tests according to Kenya National HIV testing algorithm. This repeat testing was done to confirm that the samples were all HIV positive as a requirement for downstream procedures.Re-testing for HIV was carried out with rapid test kits; Determine (Abbott Japan Co Ltd, Tokyo, Japan), SD Bioline HIV 1/2 3.0(Standard Diagnostics Inc, Kyonggi-do, Korea) and Uni-Gold HIV-1/2 test kit ((Trinity Biotech PLC,Bray, Ireland). Rapid tests for HCV used were; Bioline HCV rapid (Standard Diagnostics Inc, Kyonggi-do, Korea) and HCV PHA 2nd Generation (Dinabot Co., Ltd., Tokyo, Japan).Rapid testing for HBV involved use of Determine HBsAg (Alere, USA) and ICHEK rapid test.Syphilis rapid testing was done using Rapid Plasma Reagin(RPR) Card Tests (Becton Dickinson BD USA) and reactive results compared with VDRL(Thermo Fisher Scientific).The use of different RDTs was based on screening and confirmation strategy based on RDTs. Further testing for the analytes was carried out on ELISA based tests following manufacturer's instructions. VIRONOSTIKA HIV Uni-Form II Plus 0 (Biomerieux); Murex anti HCV version 3.0 (Abbot t Laboratories); Hepanostika ${ }^{\circledR}$ HBsAg Ultra sensitive test for Hepatitis B infection (bioMérieux) and HSVtype 2 IgG ELISA ("Kalon"; Kalon Biological Ltd, Surrey, UK) kits for HIV, HBV, HCV and HSV2 respectively were used.

\section{Data analysis}

Collected data was cleaned and association evaluated with demographic variables. Chi-square test was used to test for association for the categorical variables. Data was then presented in maps representing the sites and regions from which the participants resided.

\section{Results}

Study sites

This study involved 1829 participants distributed across 12 study sites (Figure 1.0) from across regions in Kenya. A total of 11 out of the 47 counties in 7 out of the 8 regions [former provinces] were covered except Northern Eastern region. 


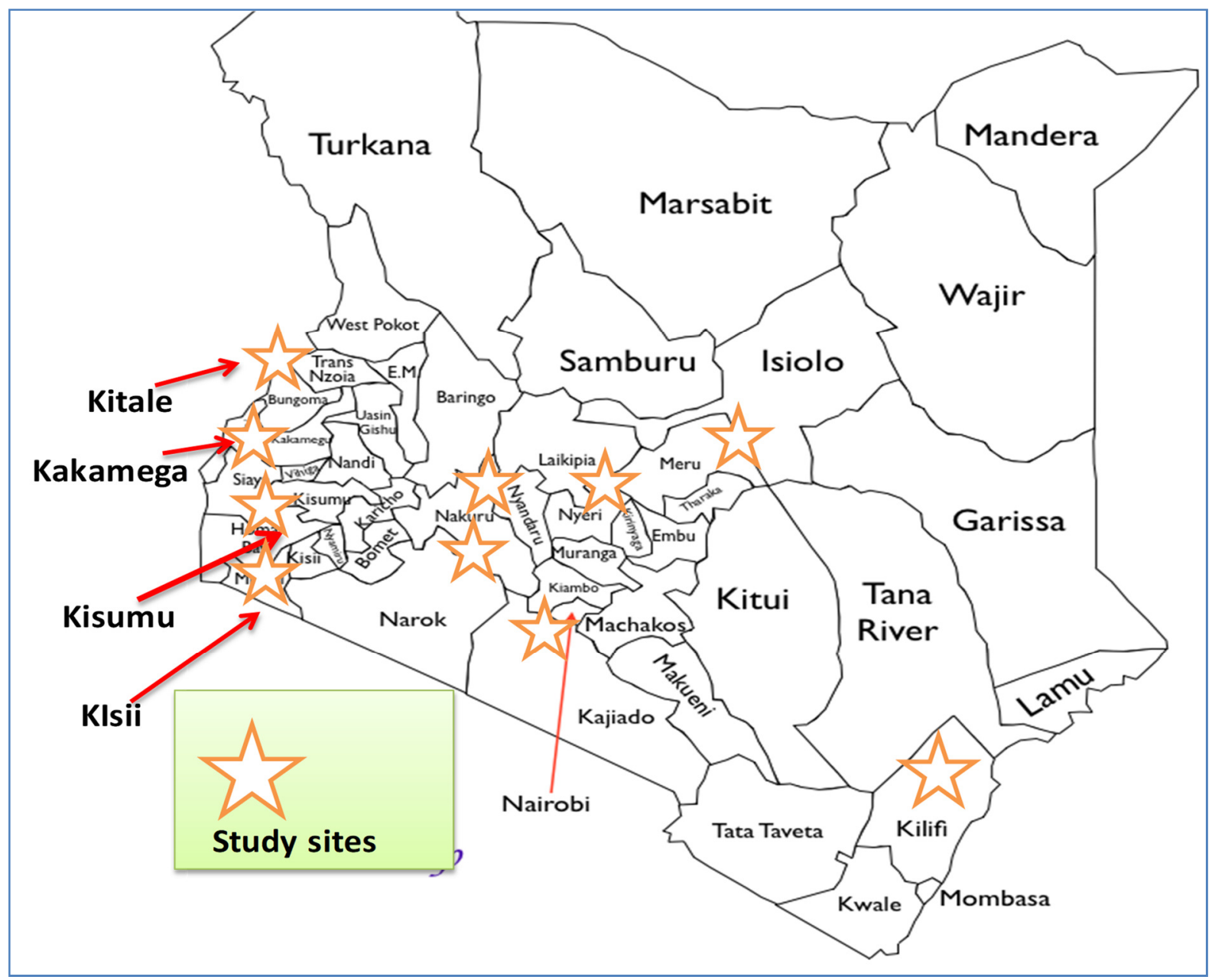

Figure 1.0: Study sites were Kakamega, Kisumu, Kisii, Kitale, Nakuru, Nyahururu, Nyeri, Nairobi BTS, Mbagathi, Meru, Mwingi and Kilifi representing 11 of the 47 counties in Kenya.

Participant's distribution by gender involved 33\% $(n=597)$ of participants were male while $67 \%(n=1232)$ were female. There was almost an equal distribution of participants within age groups except for age group $>51$ which had $9 \%$. Age groups 14-25; 26-32; 33-35 and 40-50 participants' distribution ranged 19\%-21\%. The mean age among female was 31.97, Standard deviation 12.5, at $95 \%$ CI while that of males was 32.35 standard deviation 15.1 at $95 \%$ CI.

\section{Sero-prevalence of $\mathrm{HBV}$, HCV, HSV and syphilis}

The overall prevalence of HSV2 was the highest (at $50 \%$ ) followed by that of HBV (29\%). Prevalence of HCV and Syphilis was $14 \%$ in the study population. Majority of study participants [71\%] had at least a co-infection (infection with HBV, HCV, HSV2 or syphilis or combined), the rest of the study participants (29\%) had none of any of the four infections. Segregation by gender indicated that among women $70 \%$ had at least any one of the 4 infections, compared to $72 \%$ among male. Distribution of any of the 4 infections by site, indicate Mbagathi had the highest co-infections at $80 \%$.

\section{Combinations of the co- infections among the HIV infected}

Co-infections in this study were compared between age, gender and study sites based on the four infections studied regardless of which infection to identify single, double triple and multiple infections first. In addition the occurrence of the particularly infection (HBV; HCV; HSV2 and syphilis were then identified and segregated into their combinations. In regards to age, single co-infections were more prevalent in age group above 6o years $(49.1 \%)$, by gender; males were leading $(44.7 \%)$ while in regards to sites; Nakuru and Nyahururu had more single infections at $54.2 \%$ unlike all the other sites.

Double infections were more prevalent in age group $>60(22.6 \%)$, by gender, females had more double infections (21\%), while by site Mbagathi was leading at 30.7\%.Multiple co-infections were more prevalent in age group 25-44(6.9\%), and females had more multiple infections (6.9\%), while by site, Kakamega and Kisumu had higher prevalence at $9.9 \%$ and $9.0 \%$ across sites.Combination of the 4 co-infections was more prevalent in age 
group 25-44 years $(2.1 \%)$ and by site categories Kisii had the highest (2.9\%).

\section{Map representation of the findings}

Mapping of HBV by the regions in Kenya

Generally, Sero-prevalence of HBV was high above the WHO classification, where Kenya is ranked as a high prevalence country $(>8 \%)$.Comparatively highest prevalence was recorded in Western and Nyanza regions in this study (above 31\%) (Figure 2.0).

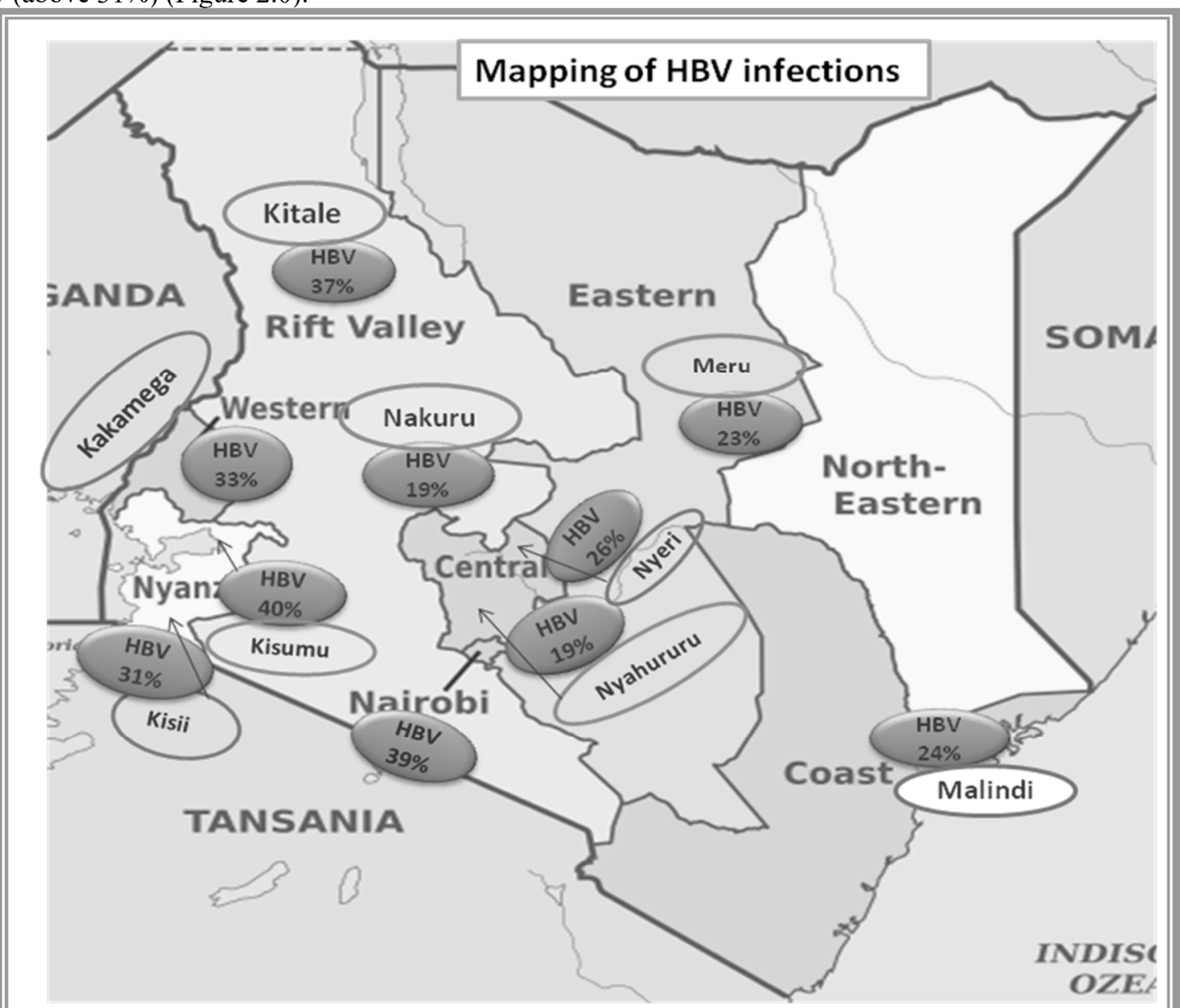

Figure 2.0 Mapping of HBV Co-infections in Kenya

\section{Mapping of HCV by the regions in Kenya}

Sero-prevalence of HCV shows a more homogenous pattern across the regions with Kisumu (19\%), Nyeri(19\%), Kitale(18\%), Meru(16\%), Malindi(15\%) and Kakamega(15\%) having the highest proportions in that order. On average, the prevalence across the regions also indicates similar homogeneity (Figure 3.0). 


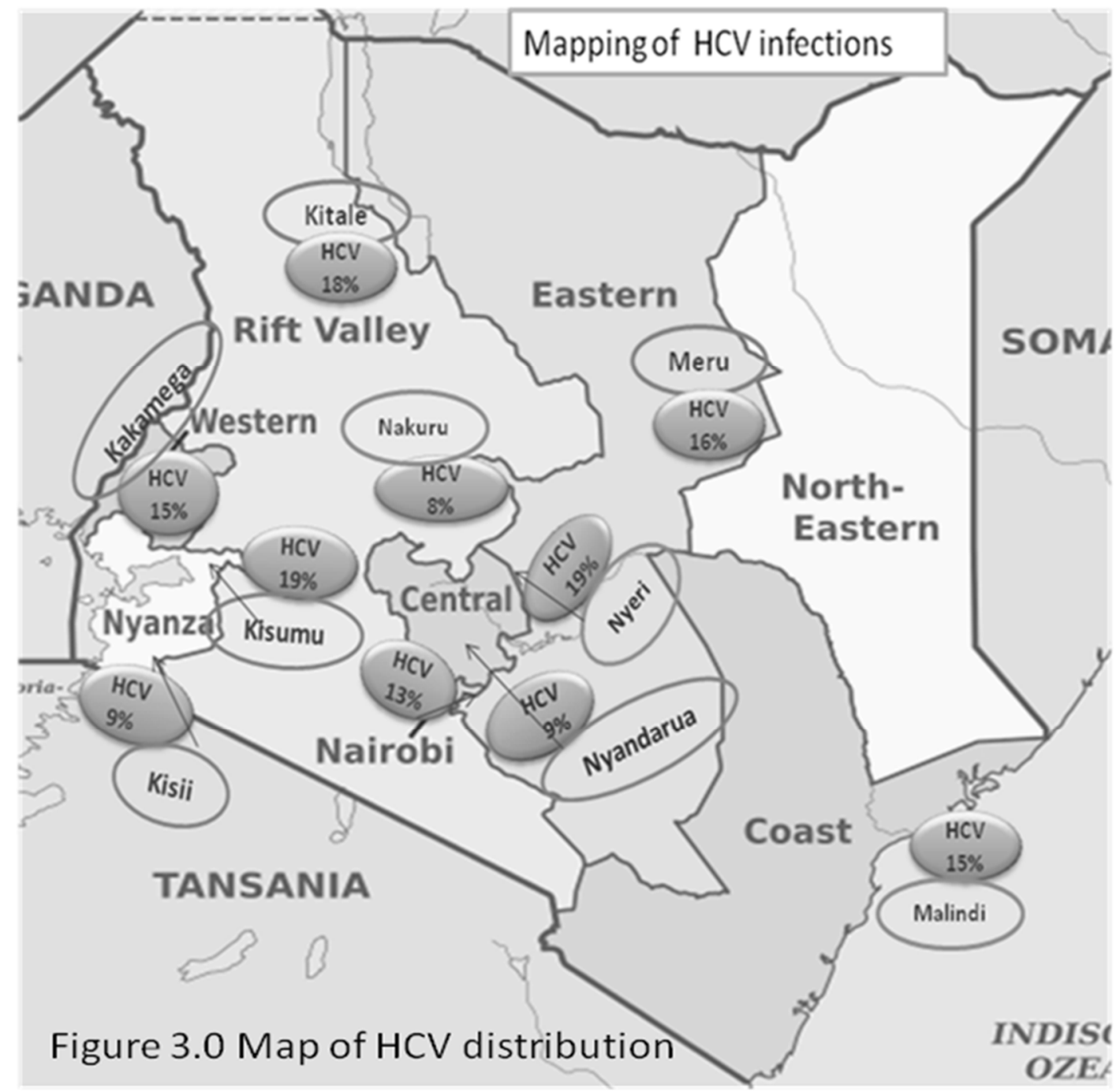

\section{Mapping of syphilis by the regions}

Syphilis sero-prevalence was highest in western and Nyanza region (Range 18\% to 26\%) compared to other regions $(4 \%$ to $15 \%)$, the lowest prevalence was recorded in Nyahururu and Nyeri, both in Central region (Figure 4.0). By average Nyanza region had $22 \%$ followed by western at $19 \%$ and Rift Valley at $17 \%$. The lowest regional average was that of Central with $6.2 \%$ prevalence (Figure 4.0). 


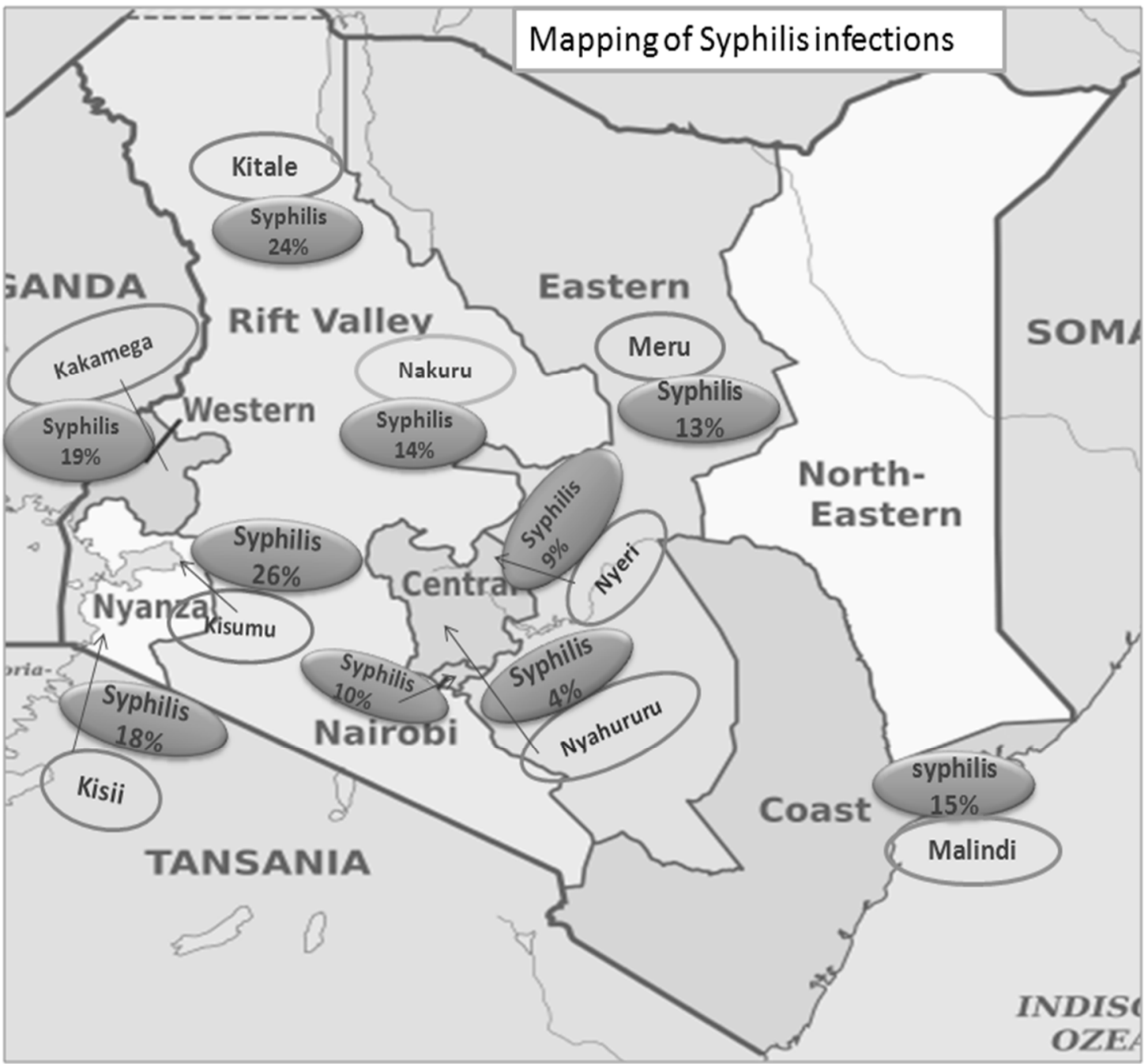

Figure 4.0Mapping of syphilis infection in Kenya

\section{Mapping of HSV infections by the regions}

HSV sero-prevalence ranged from $29 \%$ to $67 \%$ in all regions .The lowest was in Meru at $29 \%$ and the highest Nyahururu at $67 \%$. Regional averages indicate Nairobi was leading at $62 \%$, Central at $48.5 \%$ and Rift Valley at $47.5 \%$. Lowest prevalence of HSV2 was at eastern region with an average of $29 \%$ (Figure 5.0). 


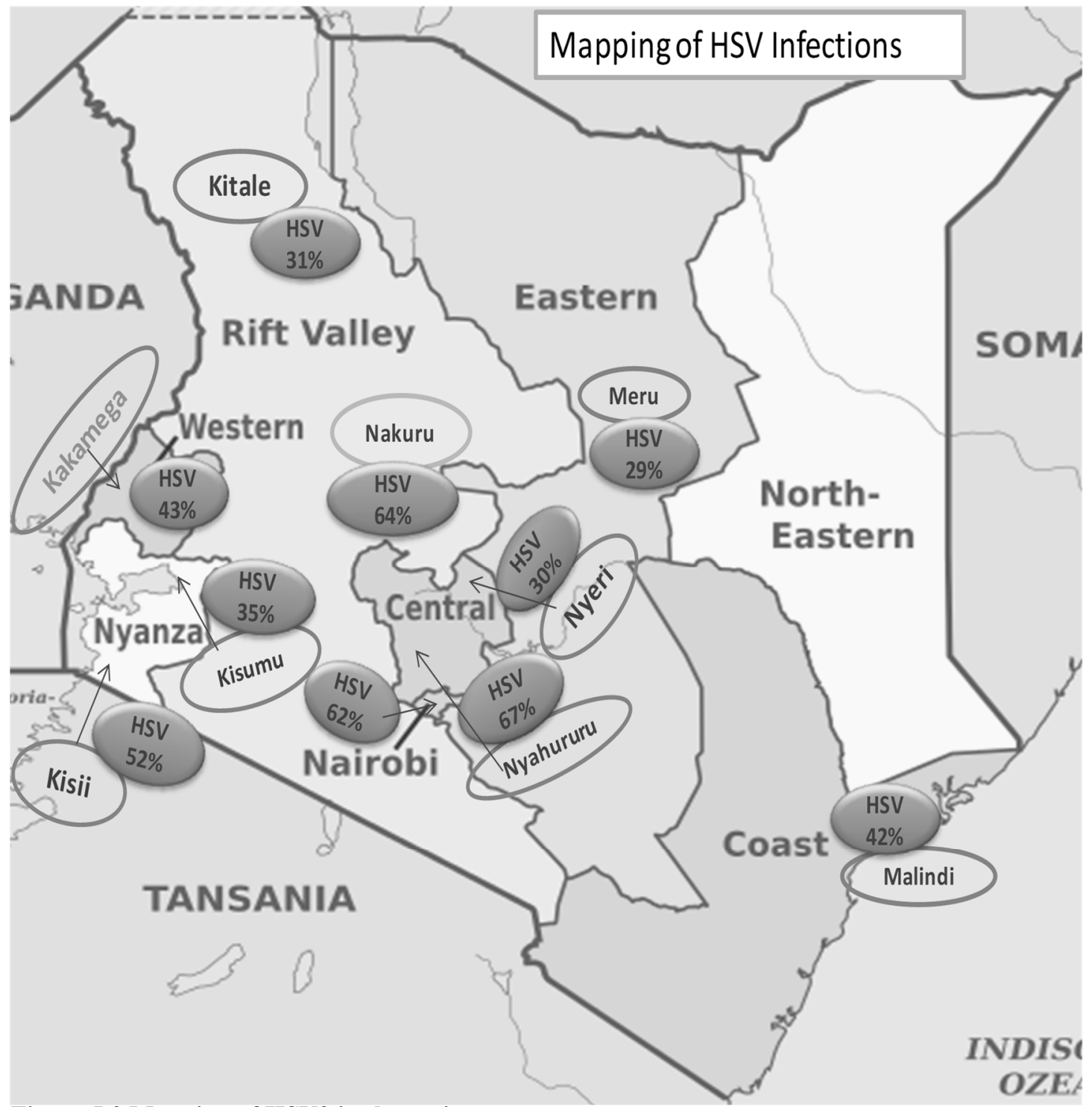

Figure 5.0 Mapping of HSV2 in the regions

\section{Correlation between infection rates and study sites}

There was significant association between the four infections and study sites; p-value 0.000 for HBV, HCV and HSV2 except for HCV (p-value-0.008).

\section{Discussion}

Co-infections are an important concern in health care management and disease control. In this study we determined sero-prevalence of viral co-infections including Hepatitis B, hepatitis C, Herpes simplex2 and syphilis-a bacterial infection.

Unlike most of other studies carried out in Kenya and elsewhere on HIV and co-infections, the current study is unique in two aspects; it was a multicentre study, with study sites drawn from across regions (formerly provinces) in the country. In addition the study also employed a relatively large sample size (1829 participants).. It thus provides results that are representative of the HIV population while encompassing the regional diversity within Kenya. This study also provides information on 5 infections [HIV, HBV, HCV, HSV2 and syphilis] unlike most other studies that dwell on two or three markers. Most co-infection studies published in Kenya include HIV, HBV and or HCV while this study had HSV2 and syphilis as an addition. The results obtained in this study are therefore more inclusive and provides the most current and diverse information on co-infections of HIV. These results therefore are likely to form basis for inferences on HIV co-infections.

The study population selected from at least 10 sites within the high population belt in Kenya had more female participants than males $(67 \%$ vs. $33 \%)$. This is despite the random selection and similar demographic profile. Since gender is a social determinant of health, perhaps, this is an indication of disparity in health seeking behavior 
between female and males in the population. Notably, the population in Kenya consist of almost equal proportions of females and males; 19.4 million female vs. 19.2 million males (KBS, 2010).

Since respondents were patients seeking HIV care services, this could also be a reflection of high infection rates among females. The latest HIV surveillance data, the Kenya AIDS Indicator survey 2012, demonstrated higher HIV prevalence among female (6.9\% vs 4.4\%; overall $5.6 \%$ prevalence) (KAIS 2012). Characterization of the study participants by mean age and age groups indicated a rather homogenous population with comparable mean age between females and males at 31.97 and 32.35 respectively. This is important when considering the distribution of co-infections across the population demographics. More important, age is a determinant factor in HIV transmission. For example, HIV prevalence increased with advancing age, peaking at 35-39 years and 4549 years among women and men respectively in Kenya (KAIS, 2012). The youth (15-24 years) contributed 51\% of adult new HIV infections in 2015(NASCOP,2016).

Findings in this study demonstrates that HSV2 is the most prevalent co-infection (50\%) among the HIV infected followed by HBV (29\%), HCV (14\%) and syphilis (14\%) in that order. Disparities were identified in the distribution of these infections by gender, age and locality. Analysis of multiple co-infections indicated, majority of individuals $(71 \%)$ had one infection or another. This finding indicates the magnitude and complexity of coinfections among the HIV infected. Single and double co-infections were common among the older participants ( $>60$ years) with $49 \%$ while multiple and quadruple infections were highest among $25-44$ year old $(6.9 \%)$. This could be due to higher risk factors associated with the latter age group.

Shared risk factors, modes of transmission for HIV, HBV, HCV, HSV and syphilis and the impact coinfections have on disease progression are important public health considerations informed by the results of this study.

Hepatitis B co-infections with HIV were the second most prevalent infections (29\%) save for HSV. Previous studies in Kenya have reported varied HBV prevalence including; $22.9 \%$ among blood donors (Nyairo et al, 2016), $50 \%$ among patients with symptoms of liver disease (Ochwoto et al, 2016); 13.3\% in informal settlements (Kerubo et al, 2015); 7\% among women on ART (Day et al, 2013) and 3.8\% among ANC women in Kenya. Results obtained in the current study indicate a higher prevalence for HBV than previously reported. The current study findings are crucial since data on co-infections among the HIV infected is limited in-country. Globally, approximately $10 \%$ of $\mathrm{HIV}$-infected patients are co-infected with $\mathrm{HBV}$. The prevalence is higher in countries endemic for chronic hepatitis B infection (CHB). This is the case in Asia and Africa, where the prevalence of coinfection has been as high as $25 \%$ (Sun et al,2014.

This study represents one of the most comprehensive efforts to provide data on the actual situation of HCV infection in Kenya. A HCV prevalence of $14 \%$ among the HIV infected was demonstrated. Previous studies from selected population groups have shown that HCV prevalence ranges from $0.7 \%$ to $0.9 \%$ among blood donors; $3.9 \%$ among patients with symptoms of liver disease (Ochwoto et al, 2016); 1.0\% (Chen et al, 2011; Harania et al, 2008); 22\% and 16, 4\% among IDUs (Mwatelah et al, 2015; Muasya et al, 2008); 0.76 among informal settlements (Kerubo et al, 2015).The findings of the current study seems consistent with that of High risk population group like IDUs. This is quite informative, since in Kenya, the assumptions have been HCV is mostly higher among most at risk populations.

Hepatitis $\mathrm{C}$ virus (HCV) infection is one of the main global health burden (Razavi et al, 2013). A countryspecific policy of prevention, diagnosis and treatment could reduce this disease burden and ensure control. Robust epidemiological data upon which to base these strategies is limited. Currently in Kenya, there is an ongoing focus on Hepatitis infections among IDUs especially, HCV. A program on special population is exploring treatment options and so far has initiated treatment within a few sites. Availability of data on HCV, as shown in this study is therefore crucial in order to plan for treatment as well as manage the infections. These results also indicate the need to consider including hepatitis in the list of program priority diseases. This has potential to give impetus to more funding and increased focus in prevention and control.

As indicated through the data generated in this study, such programs should therefore cast the net wider in other population groups where higher infections are probable.

Interestingly, the distribution of these co-infections by number (single, double, multiple and quadruple) varied with demographic characteristics. Single and double co-infections were higher among those in age group $\geq 60$ years, while multiple and quadruple infections were more common among age group 24 to 44 years( $8 \%$ vs. 3.8\%). The rate of sexual activity and probably exposure from multiple partners could explain these findings with respect to age group 24-44 years. Between gender; single and double infections were common among men, while multiple infections were common among women. These variations were however not significant (Fisher's exact test $\mathrm{p}=0.063$ for age groups; $\mathrm{X} 2=0.97,1$ d.f, $\mathrm{p}=0.325$ ). Logistic regression analysis of the variables with respect to sero-status, age and gender did not show any significant correlations

Comparison between study sites and regions indicated positive relationship, with significant differences $\left(\mathrm{X}^{2}\right.$ $=62.01,9$ d.f, $p=<0.001)$.This indicates that study sites had a statistically significant relationship $(\mathrm{p}<0.001)$, with the presence or absence of viral co-infections for a patient. For example a patient at Mbagathi had an odds 2.26 
times that of a patient in Kakamega of getting a viral co-infection ( $p=0.000$, Odds Ratio= 2.26; 95\% C. I $(1.434-$ $3.570)$, while a patient at Meru had an odds 0.49 of getting a viral co-infection $(\mathrm{p}=0.002$, Odds Ratio $=0.49 ; 95 \%$ C.I $(0.307-0.722)$. It is therefore probable that in Kenya the risks of co-infections could be associated with geographical region. This is important and validates the mapping of infections as carried out in this study. The variations detected with various demographic characteristics in this study, however, could not be attributed to any particular factors since this was beyond the scope of the study. Besides, our study indicates there's a going concern with HIV co-infections especially for Hepatitis, syphilis and HSV2.

In the context of integration of services, there's increasing need to pursue this goal since co-infections of HIV are likely to continue building up. Why not integrate HIV services with those of HBV, HCV, HSV2 and syphilis so that limited resource settings can leverage on success of HIV programming?

\section{Conclusion}

Co-infections of HIV, though mostly not given adequate attention are an important problem among patients on care. Often these infections go unnoticed since there is no routine testing nor dedicated programs in many resource limited settings. As a result testing algorithm and policy guidelines are lacking. This is an impediment to access and availability of routine tests for $\mathrm{HBV}, \mathrm{HCV}$, and HSV2 .In most cases the only routine test available is that of syphilis. In this era of rapid tests, it could be feasible to make available testing for these infections in many settings.

\section{References}

Abdool Karim, S.S., Abdool Karim, Q., Kharsany, A.B., Baxter, C., Grobler, A.C., Werner, L., Kashuba, A., Mansoor, L.E., Samsunder, N., Mindel, A. and Gengiah, T.N., 2015. Tenofovir gel for the prevention of herpes simplex virus type 2 infection. New England Journal of Medicine, 373(6), pp.530-539.

Looker, K.J., Magaret, A.S., Turner, K.M., Vickerman, P., Gottlieb, S.L. and Newman, L.M., 2015. Correction: global estimates of prevalent and incident herpes simplex virus type 2 infections in 2012. PloS one, 10(5), p.e0128615.

Todd, J., Riedner, G., Maboko, L., Hoelscher, M., Weiss, H.A., Lyamuya, E., Mabey, D., Rusizoka, M., Belec, L. and Hayes, R., 2013. Effect of genital herpes on cervicovaginal HIV shedding in women co-infected with HIV AND HSV-2 in Tanzania. PloS one, 8(3), p.e59037.

Hay, S.I., Battle, K.E., Pigott, D.M., Smith, D.L., Moyes, C.L., Bhatt, S., Brownstein, J.S., Collier, N., Myers, M.F., George, D.B. and Gething, P.W., 2013. Global mapping of infectious disease. Philosophical Transactions of the Royal Society B: Biological Sciences, 368(1614), p.20120250.

Mavilia, M.G. and Wu, G.Y., 2018. HBV-HCV coinfection: viral interactions, management, and viral reactivation. Journal of clinical and translational hepatology, 6(3), p.296.

Mutagoma, M., Balisanga, H., Malamba, S.S., Sebuhoro, D., Remera, E., Riedel, D.J., Kanters, S. and Nsanzimana, S., 2017. Hepatitis B virus and HIV co-infection among pregnant women in Rwanda. BMC infectious diseases, $17(1)$, p.618.

Saraswat, V., Norris, S., De Knegt, R.J., Sanchez Avila, J.F., Sonderup, M., Zuckerman, E., Arkkila, P., Stedman, C., Acharya, S., Aho, I. and Anand, A.C., 2015. Historical epidemiology of hepatitis C virus (HCV) in select countries-volume 2. Journal of viral hepatitis, 22, pp.6-25.

Daw, M.A., Shabash, A., El-Bouzedi, A. and Dau, A.A., 2014. Seroprevalence of HBV, HCV \& HIV co-infection and risk factors analysis in Tripoli-Libya. PLoS One, 9(6), p.e98793.

Kassa, D., Gebremichael, G., Tilahun, T., Ayalkebet, A., Abrha, Y., Mesfin, G., Belay, Y., Demissie, M., Gebrexiabher, A. and Assefa, Y., 2019. Prevalence of sexually transmitted infections (HIV, hepatitis B virus, herpes simplex virus type 2, and syphilis) in pregnant women in Ethiopia: Trends over 10 years (2005-2014). International Journal of Infectious Diseases, 79, pp.50-57.

Kassa, D., Gebremichael, G., Tilahun, T., Ayalkebet, A., Abrha, Y., Mesfin, G., Belay, Y., Demissie, M., Gebrexiabher, A. and Assefa, Y., 2019. Prevalence of sexually transmitted infections (HIV, hepatitis B virus, herpes simplex virus type 2, and syphilis) in pregnant women in Ethiopia: Trends over 10 years (2005-2014). International Journal of Infectious Diseases, 79, pp.50-57.

Kenya, A.I.D.S., 2013. Indicator survey 2012 preliminary report. Nairobi: National AIDS and STI Control Programme, Ministry of Health Kenya.

National AIDS Control Council of Kenya, 2016. Kenya AIDS Response Progress Report 2016.

Ochwoto, M., Kimotho, J.H., Oyugi, J., Okoth, F., Kioko, H., Mining, S., Budambula, N.L., Giles, E., Andonov, A., Songok, E. and Osiowy, C., 2016. Hepatitis B infection is highly prevalent among patients presenting with jaundice in Kenya. BMC infectious diseases, 16(1), p.101.

Kerubo, G., Khamadi, S., Okoth, V., Madise, N., Ezeh, A., Ziraba, A. and Mwau, M., 2015. Correction: Hepatitis B, Hepatitis C and HIV-1 Coinfection in Two Informal Urban Settlements in Nairobi, Kenya. PloS one, 10(7), p.e0133342.

Day, S. L., Odem-Davis, K., Mandaliya, K. N., Jerome, K. R., Cook, L., Masese, L. N., ... \& McClelland, R. S. 
(2013). Prevalence, clinical and virologic outcomes of hepatitis B virus co-infection in HIV-1 positive Kenyan women on antiretroviral therapy. PLoS One, 8(3), e59346.

Sun, H.Y., Sheng, W.H., Tsai, M.S., Lee, K.Y., Chang, S.Y. and Hung, C.C., 2014. Hepatitis B virus coinfection in human immunodeficiency virus-infected patients: a review. World journal of gastroenterology: WJG, 20(40), p.14598.

Chen, J.J., Yu, C.B., Du, W.B. and Li, L.J., 2011. Prevalence of hepatitis B and C in HIV-infected patients: a metaanalysis. Hepatobiliary \& Pancreatic Diseases International, 10(2), pp.122-127.

Harania, R.S., Karuru, J., Nelson, M. and Stebbing, J., 2008. HIV, hepatitis B and hepatitis C coinfection in Kenya. Aids, 22(10), pp.1221-1222.

Muasya, T., Lore, W., Yano, K., Yatsuhashi, H., Owiti, F.R., Fukuda, M., Tamada, M.Y., Kulundu, J., Tukei, J. and Okoth, F.A., 2008. Prevalence of hepatitis $\mathrm{C}$ virus and its genotypes among a cohort of drug users in Kenya. East African medical journal, 85(7), pp.318-325.

Ednah K. Nyairo, Zipporah Ng'ang'a, James Kimotho, Samoel A. Khamadi, Lihana Raphael. Missiani Ochwoto, Keith Talaam, Joseph Mwangi,Raphael Lwembe.Mutations in the "a" Determinant Region of Hepatitis B Virus.Genotype A among Voluntary Kenyan Blood Donors. Journal of Biology, Agriculture and Healthcare.Vol.6, No.14. 2016.

Mwatelah, R.S., Lwembe, R.M., Osman, S., Ogutu, B.R., Aman, R., Kitawi, R.C., Wangai, L.N., Oloo, F.A., Kokwaro, G.O. and Ochieng, W., 2015. Co-infection burden of hepatitis C virus and human immunodeficiency virus among injecting heroin users at the Kenyan Coast. PloS one, 10(7), p.e0132287.

Razavi, H., ElKhoury, A.C., Elbasha, E., Estes, C., Pasini, K., Poynard, T. and Kumar, R., 2013. Chronic hepatitis $\mathrm{C}$ virus (HCV) disease burden and cost in the United States. Hepatology, 57(6), pp.2164-2170. 